\title{
Surgically Treated Posterior Acetabular Fractures Via Iselin's Modified Approach with A Short-Term Follow-Up
}

\author{
Erdem Değirmenci ${ }^{1}$, Zafer Orhan ${ }^{1}$, Mehmet Arıcan ${ }^{1}$, Zekeriya Okan Karaduman ${ }^{1}$, Yalçın Turhan ${ }^{1}$, Ozan \\ Turhal $^{2}$ \\ ${ }^{1}$ Duzce University Faculty of Medicine, Department of Orthopaedic and Traumatology, Duzce, Turkey \\ ${ }^{2}$ Selahattin Cizrelioglu State Hospital, Department of Orthopaedic and Traumatology, Şırnak, Turkey
}

Received: 08 May 2019, Accepted: 08 July 2019, Published online: 28 August 2019

(C) Ordu University Institute of Health Sciences, Turkey, 2019

\begin{abstract}
Objective: The main purpose of the surgical treatment of posterior acetabular fracture is to achieve anatomical reduction to attain a functional and stable hip joint without pain. Although Kocher-Langenbeck (K-L) approach is the most commonly used surgical exposure, various modified approaches have been described in the literature. The aim of this study to determine the early surgical results of the acetabulum posterior fractures surgery via Iselin's modified K-L approach.

Methods: We reviewed the hospital records of patients who were operated for acetabulum posterior wall fractures via Iselin's modified approach between 2016 and 2018. All patients had detailed radiological, clinical evaluation and fractures were classified by AO/ASIF classification. All patients had radiological and clinical evaluation at the end of the postoperative $1^{\text {st }}$ year.

Results: There were 16 men and 4 women with an average age of $42.8 \pm 18.0$ (range 18-77) years. The average follow-up was $14.8 \pm 6.1$ (range 6-28) months. The right hip was involved in 12 (60\%) patients and the left in $8(40 \%)$ patients. The average operative time was $78.6 \pm 16.7$ (range, 54-115) minutes. Average blood loss during the operation was $179.22 \pm 51.9$ (range, 100-260) $\mathrm{ml}$. The postoperative reduction was graded as anatomic $(0-1 \mathrm{~mm}$ of displacement) for 17 hips and imperfect (2-3 $\mathrm{mm}$ of displacement) for 3 patients. No patient had a deep infection, implant loosening, recurrent dislocation, deep venous thrombosis (DVT), pulmonary embolism (PE) or revision fixation.

Conclusion: The modified approach of Iselin is a successful approach with its ease in the surgery of displaced fractures that extending proximally and early radiological and functional results.

Key words: Acetabulum Fracture, Posterior Wall, Modified Method of Iselin

Suggested Citation: Degirmenci E, Orhan Z, Arican M, Karaduman ZO, Turhan Y, Turhal O. Surgically Treated Posterior Acetabular Fractures Via Iselin's Modified Approach with A Short-Term Follow-Up. Middle Black Sea Journal of Health Science, 2019; 5(2): 93-99

Address for correspondence/reprints:

\section{Erdem Değirmenci}

Telephone number: +90 (505) 7310035

E-mail: erddegir@gmail.com

DOI: $10.19127 / \mathrm{mbsjohs.561885}$

\section{Introduction}

Because of their low incidence, accompanying injuries and their complex and deep anatomy, acetabular fractures are still challenging cases for the orthopaedic surgeons. The most common type of acetabular fractures is posterior wall fracture, that accounts for $25 \%$ of all (Letournel, 1992). Thirty percent of posterior wall fractures occur in single fragment; the rest is multi fragment or
\end{abstract}


contains impaction areas. In the emergency setting, orthopaedic treatment is adapted to the procedures to maintain hemodynamic stability and to improve the overall clinical status. Long-term morbidity of acetabular fractures is high when the treatment is insufficient and ineffective (Porter, 2008).

The main purpose of surgical treatment is to provide anatomical reduction and functional, stable hip joint without pain. Fracture type and dislocation, femoral head injury, intra-articular fragments, injury duration, quality of reduction, associated injuries and surgical approach are the most common factors affecting the long term results of operative treatment (Matta,1996). Despite good fracture reduction and fixation, osteoarthritis, avascular necrosis (AVN) and heterotopic ossification (HO) may cause poorer outcome (Kaempffe, 1991).

The preferred surgical approach is one of the most important step of treatment. Anatomical reduction and rigid fixation are very important criteria for a good clinical outcome in the displaced posterior acetabular fractures. Although Kocher Langenbeck (K-L) approach is the most commonly preferred surgical technique, various modified approaches have been described in the literature (Magu, 2011). The aim of this study to evaluate the early clinical and radiological results of the surgically treated posterior acetabular fractures via Iselin's modified K-L approach.

\section{Methods}

This study was carried out with the approval of the local ethics committee of clinical research of Duzce University with the decision numbered $113 / 2018$ as a retrospective clinical study. We reviewed the data of patients who underwent open reduction and internal fixation (ORIF) for posterior acetabular wall fractures via Iselin's modified approach between 2016-2018 retrospectively. The informed consent form was taken for all individuals. Exclusion criteria included patients with severe osteoporosis, low-energy trauma, pathological fractures, and previous history of hip injuries, as well as dementia and other disease processes.

The treatment protocol for fractures and hip dislocation initially involved closed reduction under sedation/anaesthesia, followed by upper tibial skeletal traction with weights ranging from 7.5 to $10 \mathrm{~kg}$.

All patients had plain pelvic radiographs (anterior-posterior, and two $45^{\circ}$ oblique Judet views) and 2 and 3-dimensional computer tomography $(\mathrm{CT})$ preoperative and fractures were classified by AO/ASIF classification.

All patients were operated by the same surgical team using the Iselin's modified $\mathrm{K}-\mathrm{L}$ surgical approach. Patients were in the prone position on the orthopaedic table with the knee flexed at $90^{\circ}$. The curved incision began about $4 \mathrm{~cm}$ from the posterior superior iliac spine and follows the demarcation line between the gluteus maximus and the gluteus medius, once the greater trochanter was reached, the incision was extended downwards as far as the gluteal plica (Figure-1). The gluteal aponeurosis was detached from the linea aspera. The musculocutaneous flap was then completely detached and two retractors were used to lift it, so as to entirely expose the external rotator muscles and the sciatic nerve. At this point, proceeding from top to bottom, it is best to section the short rotators. Thus the bone plane was revealed by placing the two retractors in the greater and in the lesser sciatic notches, straddling the spine. Observe in the surgical field with a wide view of the skeletal plane. In proximity to the angle of the greater sciatic notch, reduction procedures carried out with care, in order to avoid accidental injury to the superior gluteal artery (F1gure2).

Closed-suction surgical drains were used for 24-72h. Thorough prophylactic antibiotics, tranexamic acid and low-molecular-weight heparin (LMWH) were used during the perioperative period and LMWH continued 4 more weeks. No prophylaxis against $\mathrm{HO}$ (indomethacin or radiation) was used.

Patients were informed and encouraged to perform intermittent, pain-free quadriceps, hip and knee flexion exercises with traction starting on the second postoperative day. Partial weight bearing was permitted 6 weeks after surgery, gradually progressing to full weight bearing at 12 weeks. All patients were evaluated in the outpatient clinic once a month in the first 6 months and then once every 3 months.

For the evaluation of fracture reduction on the postoperative radiographs we used Matta's criteria. In any of the three radiographs of the hip, displacement of fracture was evaluated and recorded in millimeters for quality of reduction. $\leq$ $1 \mathrm{~mm}$ displacement defined as anatomic reduction, displacement in the range of 2 to $3 \mathrm{~mm}$ categorized as imperfect reduction, and $>3 \mathrm{~mm}$ displacement categorized as poor reduction (Matta, 1996).

Brooker et al documented the degree of $\mathrm{HO}$ classification scheme. Finally, Helfet and Ficat/Arlet stages 3 or 4 defined posttraumatic 
arthritis and femoral head AVN, respectively (Brooker,1973; Helfet,1996; Ficat 1985).

Statistical analysis was mainly conducted using Statistical Package for Social Sciences (SPSS) v. 22 software package (SPSS/PC Inc., Chicago, IL.). Continuous data were summarized as mean and standard deviation while categorical data were summarized as frequency and percentage. Fisher's
Exact test was used to analyze categorical data. $\mathrm{P}$ values below 0.05 were considered as statistically significant.

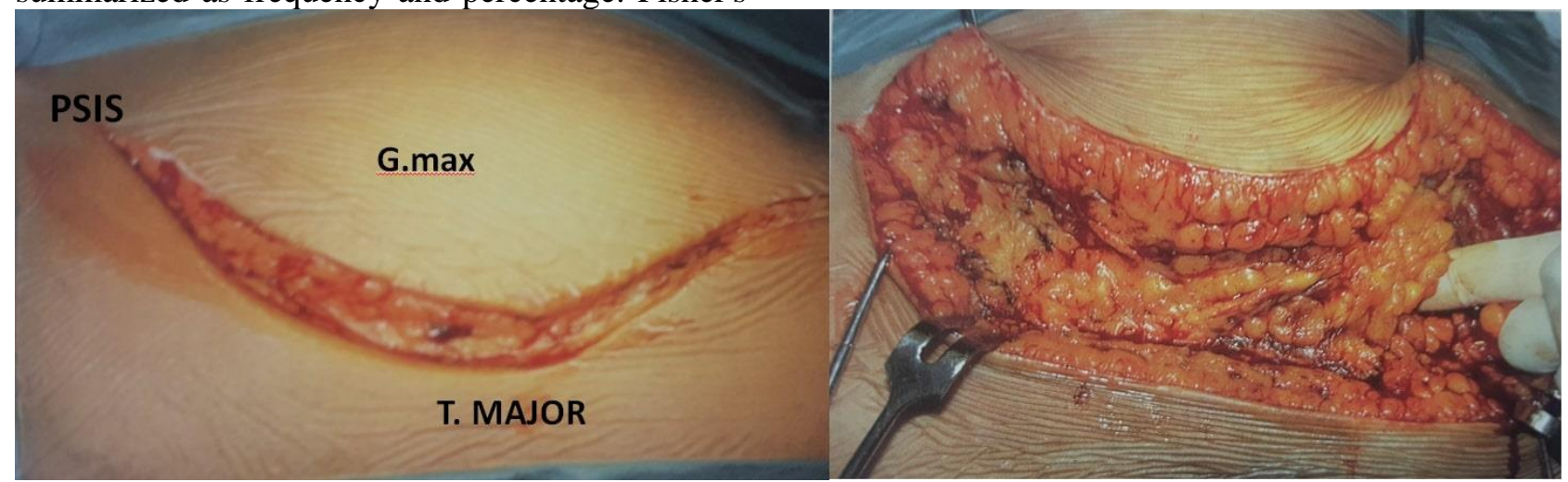

Figure -1: Incision of the modified Iselin's method: Skin incision and subcutaneous dissection. PSIS: Posteior Superior Iliac Spine G.max: Gluteus Maximus T. Major: Trochanter Major

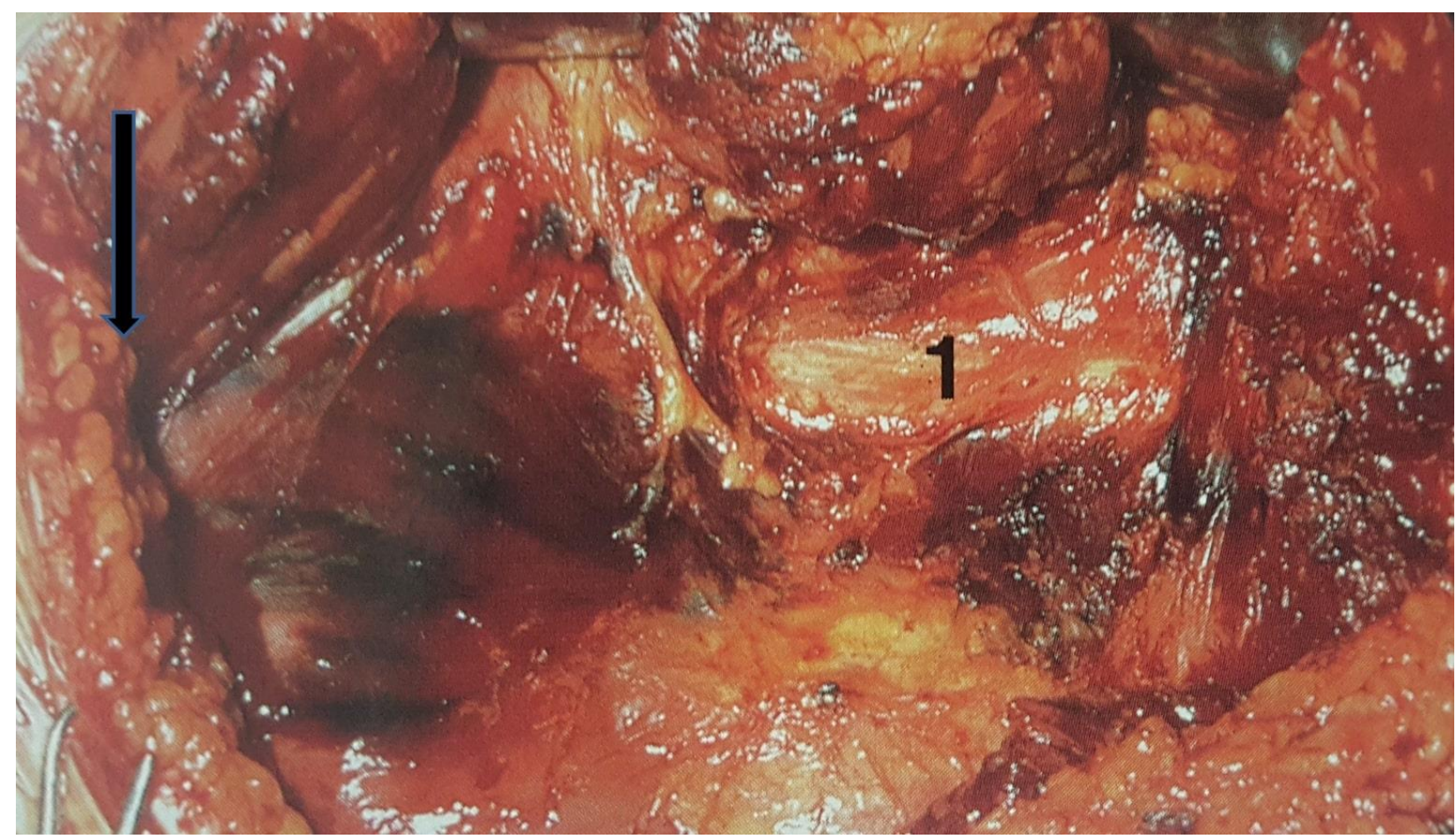

Figure-2: Deep incision 1: Siatic nerve - Arrow: Proximity of incision to superior gluteal a,v 


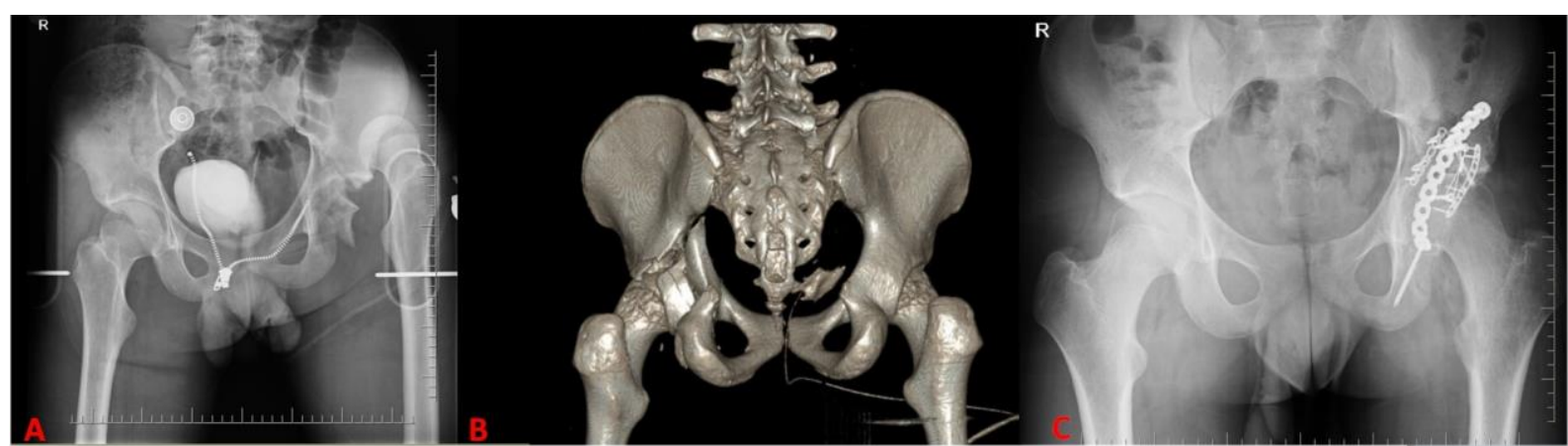

Figure-3: A: Posterior wall fracture and dislocation B: Preoperative 3-D CT screening C: Postoperative X-Ray

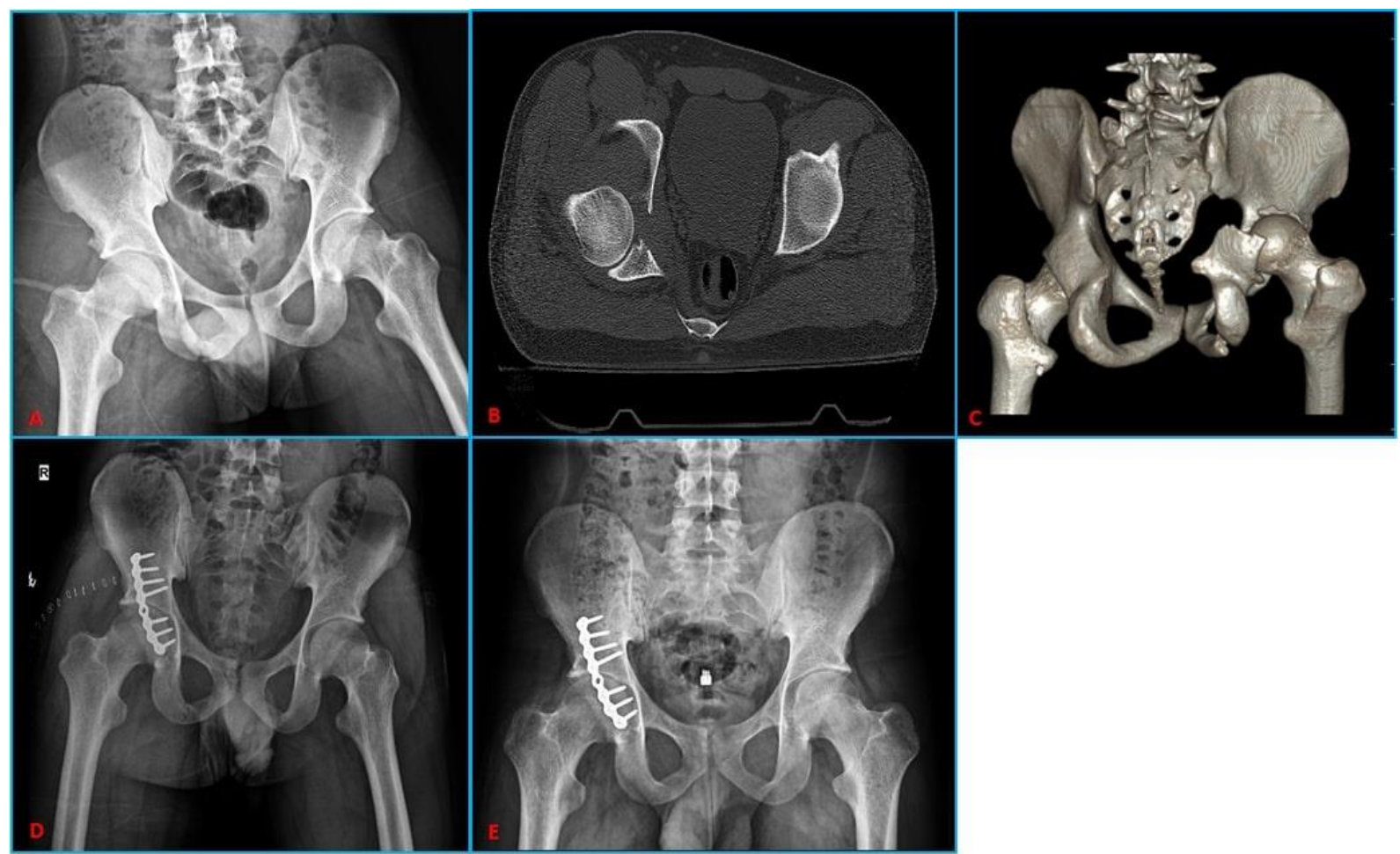

Figure-4: A: Preoperative x-ray B: Preoperative CT C: Preoperative 3-D CT screening D: Postoperative 2nd day $\mathrm{X}$-ray E: Postoperative 11 th month $\mathrm{x}$-ray

\section{Results}

Twenty patients (16 men, 4 women) were enrolled in the study. Mean age of the patients was $42.8 \pm 18.0$ years old (range $=18-77$ years old). The mean follow-up was $14.8 \pm 6.1$ (range 6-28 months) months. The operation sites were right hip in 12 patients $(60 \%)$, and left hip in 8 patients $(40 \%)$. The etiology of hip injuries were traffic accidents in $13(65 \%)$, motorcycle accident in $4(30.8 \%)$, and falls in $7(53.8 \%)$ patients. The mean time between the injury and surgical procedure was $3.2 \pm 0.8$ (range 2-5) days. (Table-1)

Preoperative evaluations revealed posterior dislocation of the injured hip in $5(25 \%)$ patients which were reduced within $12 \mathrm{~h}$ of injury. None of the patients had a fracture of the femur head. The associated injuries were present in $8(40 \%)$ patients, which included lower-extremity injuries in $6(75 \%)$ patients. The preoperative neurologic deficit of the sciatic nerve was observed in 2 patient.

Fractures were stabilized with lag screws in 5 patients and lag screws and reconstruction plate in 15 patients (Figure 3,4). The mean operation time was $78.6 \pm 16.7$ (range, 54-115) minutes. Mean blood loss during the operation was $179.22 \pm 51.9$ (range, 100-260) mL.

The postoperative reduction was graded as anatomic $(0-1 \mathrm{~mm}$ of displacement) for 17 hips and imperfect (2-3 $\mathrm{mm}$ of displacement) for 3 patients. None of the patients had a deep infection, implant loosening, recurrent dislocation, deep venous thrombosis (DVT), pulmonary embolism (PE) or revision fixation.

At the last follow-up visit, Matta's radiographic outcomes (Matta,1996) revealed excellent results 
in 11 hips, good in 5, fair in one and poor in three. Final Harris hip scores were excellent in 14 hips, good in 2, fair in 2 and poor in 2 (Table-2).

In patients with anatomical reduction, AVN was seen only $1(5.9 \%)$ patient and in $2(66.7 \%)$ patients in the imperfect group. The anatomical reduction was found to be associated with better short term functional outcome compared with nonanatomical reduction $(\mathrm{p}=0.004)$. Moreover, the presence of associated injuries in the lower limbs adversely affected the final functional outcome in these patients when compared with the patients suffering from isolated posterior wall fracture $(p=0.046)$. Quality of reduction directly affected the functional outcomes of our patients

\section{Discussion}

Although there are multiple factors affecting the surgical outcome of acetabular fractures, the proper surgical approach is very important for anatomic reduction and stable fixation.
The most commonly used approach for posterior acetabular fractures is the K-L incision but there are many modified approaches defined in the literature (Brooker,1973; Helfet,1996; Ficat,1985; Moed,2002; Magu,2011). The aim of all these new methods is to have less surgical complications with convenient access to the fracture site, stable fixation and effective use of fixation materials.

The defined modified approaches have various advantages and disadvantages. In literature, complications of various posterior approaches were reported at a frequency of $18-32 \%$, including HO, iatrogenic sciatic nerve palsy, AVN, posttraumatic osteoarthritis (Baumgaertner, 1999).

Sciatic nerve damage is one of the most important complications of posterior acetabular approaches. Iatrogenic sciatic nerve palsies were reported with an incidence of $3 \%$ to $18 \%$ in literature (Kaempffe,1991; Giannoudis,2005).

Table 1 Clinico-radiological workup of patients with acetabular fractures

\begin{tabular}{|c|c|c|c|c|c|c|c|c|}
\hline Sr. & Sex/Age & $\begin{array}{l}\text { Postoperative } \\
\text { reduction }\end{array}$ & $\begin{array}{l}\text { Associated } \\
\text { lower-limb } \\
\text { injury/Dislocation }\end{array}$ & BMI & Complications & $\begin{array}{l}\text { Follow- } \\
\text { up } \\
\text { (month) }\end{array}$ & $\begin{array}{l}\text { Final } \\
\text { radiological } \\
\text { outcome }\end{array}$ & $\begin{array}{l}\text { Harris } \\
\text { Hip } \\
\text { Score } \\
\end{array}$ \\
\hline 1 & $38 / \mathrm{M}$ & Anatomical & Tibia plateu & 36,3 & - & 24 & Excellent & Excellent \\
\hline 2 & $18 / \mathrm{F}$ & Anatomical & Dislocation & 19,9 & - & 6 & Excellent & Excellent \\
\hline 3 & $42 / \mathrm{M}$ & Anatomical & - & 26,4 & - & 14 & Excellent & Excellent \\
\hline 4 & $31 / \mathrm{M}$ & Imperfect & IL/ Fem neck & 24,2 & AVN & 12 & Poor & Poor \\
\hline 5 & $66 / \mathrm{M}$ & Anatomical & Tibia shaft & 27 & - & 28 & Good & Good \\
\hline 6 & $50 / \mathrm{M}$ & Anatomical & - & 28,2 & - & 24 & Excellent & Excellent \\
\hline 7 & $49 / \mathrm{F}$ & Anatomical & - & 29,7 & - & 16 & Excellent & Excellent \\
\hline 8 & $45 / \mathrm{M}$ & Anatomical & - & 27,8 & - & 17 & Excellent & Excellent \\
\hline 9 & $21 / \mathrm{M}$ & Anatomical & Dislocation & 25,9 & $\begin{array}{l}\text { Sciatic } \\
\text { neuropraxia }\end{array}$ & 18 & Excellent & Excellent \\
\hline 10 & 20/M & Imperfect & IL/ Femur shaft & 22 & AVN & 12 & Poor & Good \\
\hline 11 & $22 / \mathrm{M}$ & Anatomical & - & 23,4 & - & 9 & Fair & Excellent \\
\hline 12 & $59 / \mathrm{M}$ & Anatomical & - & 24,7 & - & 8 & Excellent & Excellent \\
\hline 13 & $46 / \mathrm{M}$ & Imperfect & Dislocation & 24,2 & Cocxarthrosis & 14 & Poor & Poor \\
\hline 14 & $66 / \mathrm{M}$ & Anatomical & - & 31,2 & - & 12 & Excellent & Excellent \\
\hline 15 & $77 / \mathrm{F}$ & Anatomical & IL/ Fem neck & 30,9 & - & 16 & Good & Good \\
\hline 16 & $24 / \mathrm{M}$ & Anatomical & Dislocation & 27,1 & AVN & 12 & Good & Fair \\
\hline 17 & $40 / \mathrm{M}$ & Anatomical & Dislocation & 24,7 & Sciatic & 13 & Good & Excellent \\
\hline 18 & $54 / \mathrm{M}$ & Anatomical & - & 30,1 & neuropraxia & 14 & Excellent & Excellent \\
\hline 19 & $43 / \mathrm{F}$ & Anatomical & IL/ Femur shaft & 22 & - & 12 & Excellent & Excellent \\
\hline 20 & $35 / \mathrm{F}$ & Anatomical & - & 23 & - & 11 & Good & Excellent \\
\hline
\end{tabular}

$\underline{\text { Table } 2 \text { Radiological and functional outcome of patients at final follow-up }}$

\begin{tabular}{|c|c|c|c|c|c|c|c|c|c|c|}
\hline \multirow{2}{*}{$\begin{array}{l}\text { Fracture } \\
\text { Reduction }\end{array}$} & \multicolumn{4}{|c|}{ Radiological Outcome } & \multicolumn{4}{|c|}{ Functional Outcome } & \multirow{2}{*}{\multicolumn{2}{|c|}{ AVN $\quad$ HO }} \\
\hline & Excellent & Good & Fair & Poor & Excellent & Good & Fair & Poor & & \\
\hline Anatomical & 11 & 5 & 1 & - & 14 & 2 & 1 & - & 1 & - \\
\hline Imperfect & - & - & - & 3 & - & 1 & - & 2 & 2 & - \\
\hline
\end{tabular}

AVN: Avascular Necrosis HO: Heterotopic Ossification 
Stretching of the retractor placed in the sciatic notch during the surgical procedure or the reduction of unstable posterior colon fracture can cause injury of the sciatic nerve. In the Iselin's approach, gluteus maximus muscle is detached at the beginning of the surgery and nerve is dissected by a finger that allows the safe insertion of the retractors to the sciatic notches. In our cases, sciatic nerve neuropraxia was detected in 2 patients with posterior fracture and dislocation and recovered at 6 months after the accident. None of the patients had iatrogenic nerve injury.

Surgery time and amount of blood loss are important parameters for early postoperative hemorrhagic shock and infection. Although the accident and fracture mechanisms are mentioned as the main reasons in the literature, iatrogenic vascular injuries are also an important factor (Rommens, 2004). It has been mentioned that there may be a superior gluteal artery injury in the proximal part of the incision in Iselin method (Zinghi,2004). By careful dissection, no iatrogenic vascular injury or postoperative hemorrhagic shock were observed in our cases. If surgical approach provides safety and easy reach to the fracture site, it shortens the surgery time and thus decreases the associated complications such as hemorrhagic shock, wound infection and PE (Carr, 2006).

In our study, the mean interval between injury and the surgical procedure was found to be 3.2 days with a mean surgical time of 79.8 minutes, and blood loss of $179.15 \mathrm{cc}$. The time of surgery and amount of bleeding are lower than the average of the standard and modified approaches specified in the literature, in particular (Negrin, 2017). Complications such as DVT and PE, which were reported as $8 \%$ in the literature, were not detected in any of our cases (Negrin, 2017). In 2 patients, superficial wound infections were observed and the mean duration of surgery and total blood loss were up to the average (Magu,2011). Regarding our results, we hypothesized that the mechanism of injury, the interval between injury and the surgical procedure are important parameters in the risk of complications.

Body mass index (BMI) and advanced age are the personal characteristics that can affect the surgical outcome. In elderly patients with anatomical reduction, the presence of associated injuries in lower limbs and a BMI >25 adversely affected the final functional outcome (Magu,2014). This group of patients should be advised about weight loss.

The goal of operative treatment is to achieve precise anatomical reduction to attain a painless, mobile and stable hip joint. Arthosis, AVN and HO are complications that can develop even in case of a good reduction, stable fixation, and can worsen the clinical outcome (Harris, 1969). In patients with anatomical reduction, we recorded $93 \%$ excellent or good results in Harris hip score, whereas there were worse clinical results in all of the patients with poor reduction.

In the early postoperative period, the femoral head AVN is an important complication that adversely affects the clinical outcome. This complication has a frequency of $2-10 \%$. Possible associations leading to this complication are reported as injury mechanism, and iatrogenic injury of the medial circumflex femoral artery (Im,2004). Giannoudis,2005 and Negrin,2017 reported approximately $20 \%$ posttraumatic osteoarthritis and 5,5\% AVN in their series. In our study, $85 \%$ anatomic and $15 \%$ imperfect reductions were determined in the postoperative radiological evaluation according to the Matta classification. The mean Harris hip score was found to be 89.25 at 12 months postoperatively. This ratio is consistent with the literature data. Four patients underwent total hip arthroplasty, in whom 3 had AVN of the femoral head and one had coxarthrosis. Among these patients, all had a history of motorcycle accident as the cause of fracture and dislocation.

Heterotopic ossification was reported as $4 \%$ to $31 \%$ after the surgery of posterior acetabular fractures and racial features, wide incisions and dissection of gluteus minimus muscle during the surgery were also reported to be a factor of this complication (Ghalambor, 1994). All patients in our study were white and gluteus minimus dissection was performed according to the location of the fracture line and no prophylactic medication was introduced. There were no HO in our patients. However, short-term follow up may be the limitation of our study restricting the results. As previously stated in the literature, HO cases may evolve 22 years after surgery (Liebergall,1999; Chiu, 2000).

Limitations of our study can be summarized as the study design which was conducted retrospectively, not comparing the results with patients operated on through the conventional Kocher- Langenbeck approach and the relatively small population size. However, these are limitations in most series on acetabular posterior wall fractures (Iselin,2013; Magu,2014;). 


\section{Conclusion}

An appropriate surgical approach is the major predictor of stable fixation and successful clinical outcome in posterior acetabular wall fractures. The modified approach of Iselin is a successful approach with its ease in the surgery of displaced fractures that extend proximally. Furthermore it has good clinical and radiological outcomes

Ethics Committee Approval: Ethics committee approval was received for this study from Clinical Research Ethics Committee of Düzce University. Ethics no: 113/2018

Peer-review: Externally peer-reviewed.

Author Contributions: Concept - E. D, Design E. D; Supervision Z. O; Materials - M. A; Data Collection and/or Processing - Z.O. K; Analysis and/or Interpretation- E. D, Y. T. Literature Review - O.T; Writing - E. D; Critical Review Z. O.

Conflict of Interest: No conflict of interest was declared by the author.

Financial Disclosure: The authors declared that this study hasn't received no financial support.

\section{References}

Baumgaertner MR. Fractures of the posterior wall of the acetabular. J Am Acad Orthop Surg 1999; 7:54-65.

Brooker AF, Boweman JW, Robinson RA, Riley LH Jr. Ectopic ossification following total hip replacement. Incidence and a method of classification. J Bone Joint Surg Am 1973;55(8):1629-32.

Carr JB, Leach PB. Small-incision surgical exposure for select fractures of the acetabular: The gluteus maximus-splitting approach. J Orthop Trauma. 2006; 20:573-75.

Chiu FY, Chen CM, Lo WH. Surgical treatment of displaced acetabular fractures: 72 cases followed for 10 (6-14) years. Injury 2000; 3:181-85.

Ficat RP. Idiopathic bone necrosis of the femoral head. Early diagnosis and treatment. J Bone Joint Surg (Br) 1985;67(1):3-9.

Ghalambor N, Matta JM, Bernstein L. Heterotopic ossification following operative treatment of acetabular fracture. An analysis of risk factors. Clin Orthop 1994; 305: 96-105.

Giannoudis PV, Grotz MR, Papakostidis C, Dinopoulos H. Operative treatment of displaced fractures of the acetabular. A meta-analysis. J Bone Joint Surg Br 2005;87: 2-9.
Harris WH. Traumatic arthritis of the hip after dislocation and acetabular fractures: treatment by mold arthroplasty: an end-result study using a new method of result evaluation. J Bone Joint Surg Am 1969;51(4):737-55.

Helfet DL, Shonnard P. Mini-symposium: Acetabular fracture classification. Curr Orthop 1996;10: 6973.

Im GI, Chung WS. Fractures of the posterior wall of the acetabular: Treatment using cannulated screws. Injury 2004; 35 :782-86.

Iselin LD, Wahl P, Studer P, Munro JT, Gautier E. Associated lesions in posterior wall acetabular fractures: not a valid predictor of failure. J Orthopaed Traumatol 2013; 14(3):179-84.

Kaempffe FA, Bone LB, Border JR. Open reduction and internal fixation of acetabular fractures: heterotopic ossification and other complications of treatment. J Orthop Trauma 1991; 5(4):439-45.

Letournel E, Judet R. Fractures of the acetabular. Second Edition. Berlin: Springer-Verlag; 1992.

Liebergall M, Mosheiff R, Low J, Goldvirt M, Matan Y, Segal D. Acetabular fractures: Clinical outcome of surgical treatment. Clin Orthop Relat Res 1999; 366:205-16.

Magu K.N, Paritosh Gogna, Singh G.A, Singla R, Rohilla R, Batra A. et al. Long term results after surgical management of posterior Wall acetabular fractures. J Orthopaed Traumatol 2014; 15 :17379.

Magu NK, Rohilla R, Arora S, More H. Modified Kocher- Langenbeck approach for the stabilization of posterior wall fractures of the acetabulum. J Orthop Trauma 2011; 25: 243-49.

Matta JM. Fractures of the acetabular: accuracy of reduction and clinical results in patients managed operatively within three weeks after the injury. J Bone Joint Surg Am 1996; 78: 1632-45.

Moed BR, WillsonCarr SE, Watson JT. Results of operative treatment of fractures of the posterior wall of the acetabular. J Bone Joint Surg Am 2002; 84 :752-58.

Negrin L, Seligson D. Results of 167 consecutive cases of acetabular fractures using the KocherLangenbeck approach: a case series. Journal of Orthopaedic Surgery and Research 2017; 12: 66.

Porter SE, Schroeder AC, Dzugan SS, Graves ML, Zhang L, Russell GV. Acetabular fracture patterns and their associated injuries. J Orthop Trauma 2008; 22: 165-70.

Rommens PM. The Kocher-Langenbeck approach for the treatment of acetabular fractures. Eur J Trauma 2004; 30: 265-73.

Zinghi G.F, Bungaro P, Davoli O, Ponziani L, Rollo G, Trono M. Editors. Second Edition. Fracture of the pelvis and acetabular. Georg Thieme Verlag 2004. p. 123 . 